\title{
Viable Systems Modelling for Climate Change Adaptation in the Gippsland Region
}

\author{
$\underline{\text { G.A. Moore }}^{1}$, C.F. Duffield ${ }^{1}$, D.I. Wilson ${ }^{1}$, R. Faggian ${ }^{2}$ and V. Sposito ${ }^{2}$ \\ ${ }^{1}$ Melbourne School of Engineering, University of Melbourne ${ }^{2}$ Victorian Department of Primary Industry. \\ Email: grahamam@unimelb.edu.au
}

\begin{abstract}
This paper presents the creative use of Viable Systems Modelling (VSM) as a mechanism to help multiple interest groups develop a strategy for land use adaptation to climate change for the Victorian region of Gippsland. VSM is a technique for representing systems developed by Stafford Beer from the 1960s with a strong grounding in the cybernetics discipline (Beer 1966). Originally derived by examining organisms such as humans as a system, the conceptual framework of a recursive hierarchy where any system can be considered part of a supra-system and made up of sub-systems was formed. For a system to be 'viable', Beer and his colleagues established a number of requirements or laws about the sub-systems and information channel characteristics that join them. Furthermore, each of the sub-systems could be considered a viable system in its own right due to the nested nature of the structure of systems. Since the early development, Beer and many others have applied the theory of VSM to organisational management as a means to either design the structure of business or government organisations, or alternately to examine existing organisations with the view to diagnosing why they may not be viable. While there has been some application of VSM to government organisations, there has been only a few instances published where VSM has been applied to natural resource management problems (NRM).
\end{abstract}

At the invitation of a group of local governments in Gippsland, Victoria, we have commenced the task of modelling the Gippsland Region as a viable system. Two subsystems of the Gippsland Regional System were chosen to demonstrate the approach. Agriculture, with the system in focus being a generic farm was chosen because it is intimately involved with natural resource management, economic production, and the social fabric of the region. Agriculture is also predicted to be subject to significant change over the coming decades especially due to climate change with possible large shifts in the optimum produce likely. Secondly, the government service industry, with the system in focus being local government was chosen because of its essential role in providing local infrastructure and planning strategies to allow the community and business (including farms) to exist and prosper. A critical aspect of VSM includes defining the best information that needs to flow between the sub-systems and the operating environment, and between different levels in the recursion to allow components to make effective decisions. To help structure this aspect of the research, an approach by (Bossel 2001) to define basic orientors of a system was used. For a system to be viable, 6 or 7 orientations of a system must be satisfied. These range from aspects such as resource use efficiency, to adaptability, and for sentient systems psychological wellbeing. For each of the orientors, indicators or indices are devised to capture the essence of the information about the system's response to the environment, which can collectively be used to judge the viability of the system. We contend that a system can be viable only if it has a viable structure as outlined by Beer and each of the orientations of the system and sub-system are in a satisfactory state as determined by Bossel's indicators.

Considering the farm system, it is largely concerned with taking information and resources from the broader operating environment in order to undertake operations that are productive in the economic, social and natural resource management contexts. On the other hand, the local government system is largely about manipulating the broader environment, for example through infrastructure provision, to enable systems like farms to operate effectively. In order for local government to make resilient and effective decisions it must have a source of information about the systems it serves. We propose that a regional information system, from which farms and council can draw information about the their viability and farms can supply information about risks to their viability is the way forward is the way forward to support the decision making of both councils and farms. In particular, local government can seek information on risks to viability in the region in order to plan transformative adaptation responses to climate and structural change, and avoid the likelihood of investing in stranded assets.

Keywords: Viable Systems Modelling (VSM), indicators, local government, resilience, complex systems 


\section{INTRODUCTION}

Regional development in the face of rapid change due to structural adjustments and climate change is an issue that many planners, politicians and businesses confront. It is a so-called wicked issue. Wicked problems were first described in the context of planning by (Rittel and Webber 1973). They were dubbed as wicked not in the sense of the word meaning evil or sinful, but more in the context of distressing and mischievous. A primary characteristic of wicked problems as conceived by (Rittel and Webber 1973) was that different stakeholders could not agree on what the definition of the problem and consequently could not agree on a solution. Other characteristics stem from the issue of problem definition such as being unclear if the problem is solved and action to solve a problem creating new problems. (Bawden et al. 2010), drawing on his knowledge of systems thinking, prefers to use the term 'wicked issue' rather than 'wicked problem' because our language infers that problems are matched with solutions. However, as mentioned, in any one instance, there is a plurality of problems defined by various stakeholders. Therefore the term 'issue' capture the situation more aptly and also hints to the idea that an issue can be changed and hopefully improved rather than solved.

The Australian Public Service Commission (APSC 2007) wrote a review of wicked issues from the perspective of government. They concluded that to tackle wicked issues one needed holistic rather than linear thinking, the ability to work across boundaries, and effective engagement of stakeholders in understanding the issue so that the almost inevitable behavioral change required to shifting the issue would come from solid foundations. Furthermore, long-term focus was needed because the issue would evolve rather than be solved.

(Jackson 2003) reviews a range of approaches to investigating systems. He classed the domain of systems into two dimensions - the level of complexity of systems (simple and complex) and the plurality of participant objectives (unitary, pluralist, and coercive) - shown in Figure 1.

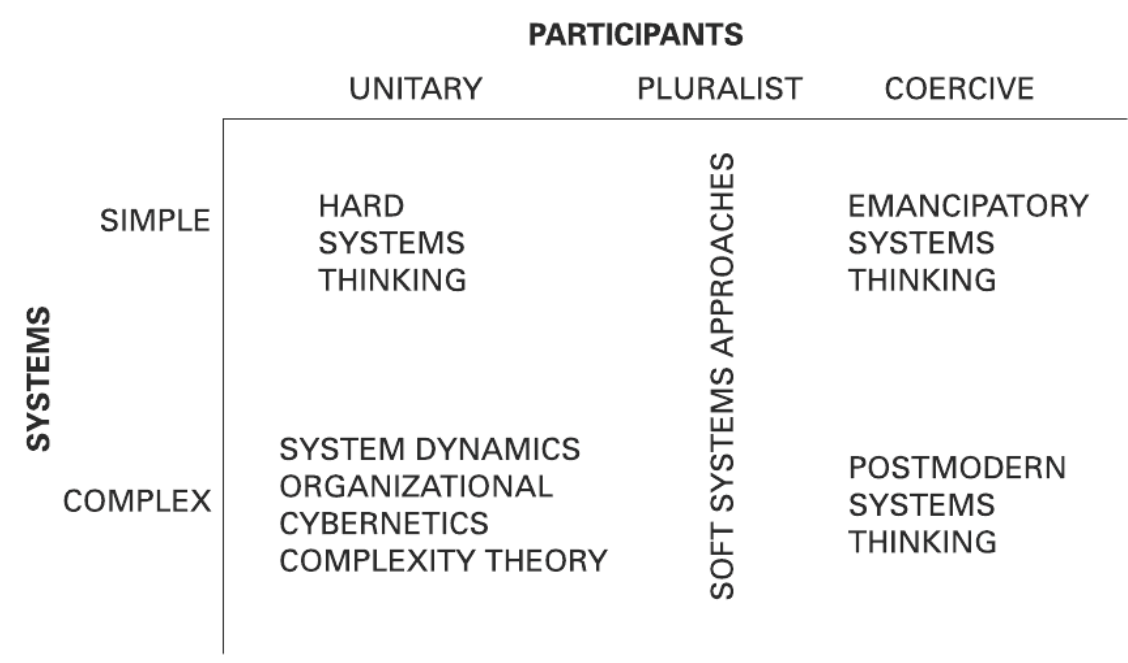

Figure 1 Classification of systems approaches to studying problems of varying complexity and objectives. (Jackson 2003)

If the objective of the participants is unitary then there is probably a clear consensus among the stakeholders of the problem definition and it is therefore a tame, rather than wicked, problem. If the system is relatively simple, or can be simplified, with only a few components and interactions then 'hard systems thinking' is the most appropriate means of investigating the system behavior. Many of the simulation modeling presentations at this conference would fit in this category. As the complexity of the system increases due to an increasing number of subsystems and interactions between the subsystems new system investigation tools were devised such as system dynamics, organization cybernetics and complexity theory. As one goes along this thought axis the investigations tend to go from quantitative to conceptual because of the difficulty in measuring the system state and predicting interactions. Complex systems are akin to quantum physics and Heisenberg's Uncertainty Principle in that it is not possible to fully characterize the current state and the future trajectory of the system.

If the stakeholder objectives are not clear then a system can be described as pluralist or coercive. Coercive systems exist where different stakeholders have different objectives and one stakeholder has much greater power to impose their objective on the other stakeholders. As such these systems can be treated as unitary systems, albeit some stakeholders will not be satisfied with the outcomes of any 
analysis. Methods to investigate coercive systems deliberately seek to identify those participants in the system with less power and determine how they are affected.

Checkland (2000) characterizes pluralist systems as having stakeholders with multiple objectives, but with appropriate discussion, can come to consensus on a single objective for at least part of the issue being dealt with. This then allows a solution to be pursued and the issue modified to allow further development of the objectives.

In our project we are investigating a regional system defined by the geographic region of Gippsland, Victoria. Garnaut (2011) identifies that significant investment in the electricity industry is required and that new investment will tend towards lower carbon dioxide emissions intensity by moving to fuels such as gas. For Gippsland this is likely to mean significant structural change because the most significant item in the Gippsland economy is the mining of brown coal for electricity production. Two other significant industries in the region are forestry, which supports a large pulp and paper mill, and agriculture, which concentrates on grazing for dairy production and some horticulture. Both of these are at the mercy of changing climatic conditions.

Naturally enough governments at all levels are interested in assisting the region transform over time to avoid major social, economic and biophysical environment dislocations or failures. However, the stakeholders of the region understandably have quite different views on the objectives of the subsystems within the region and therefore find it difficult to prioritize investment such as that currently available from Regional Development Australia.

In order to take the holistic view encouraged by the public service commissioner (APSC 2007) the Gippsland Local Government Network, a network of the 6 local government councils in Gippsland, joined with the Department of Primary Industry Victoria and the University of Melbourne to investigate the issue. Soft Systems Methodology is being used to discuss the issue with the stakeholders in order to try to find common objectives, hard systems approaches to generating climate and biophysical scenarios, and Viable Systems Modeling to characterize the organizational aspects of the system. The remainder of this paper will discuss the Viable Systems Model, which fits into the organizational cybernetics part of Figure 1, and how it can be used in a natural resource management context.

\section{CLIMATE CHANGE AND GIPPSLAND}

Concurrent work is being undertaken to determine the likely climatic changes across the Gippsland region, using the CSIRO Mk3.5 Climate Model (Gordon et al., 2010) in conjunction with the IPCC's A1FI scenario. The model output was statistically downscaled to a resolution of $5 \mathrm{~km}^{2}$, and provided estimates of nine climatic variables for the years 2030, 2050 and 2070.

The preliminary climate projections indicate a) an increase of 1 degree $\mathrm{C}$ to 1.5 degrees $\mathrm{C}$ in maximum, and mean, temperatures between each successive time period, compared to a baseline taken as the average from the period 1996 to 2005 and b) a decrease in total rainfall of $50 \mathrm{~mm}$ to $200 \mathrm{~mm}$ between each successive time period, with significant spatial variability across the region.

Changing climate will change the mixture of crops that are suitable in the region as well as also increasing the incidence of heat related health events. There will also be changes in the bio-system of natural pests and plant diseases that are associated with warmer temperatures. Figure 2 shows the projected changes in maximum temperature in 2050.

The projected decrease in rainfall for the region will have a synergetic effect when combined with temperatures to alter the agricultural regime significantly. Farmers and businesses will have to adapt to these changes as the region becomes warmer and drier. Monoculture farming as currently practiced by many farmers in the region will be vulnerable to these changes. The central question is how to assist farmers and other stakeholders in the region to begin to think about change and future scenarios. To achieve this we have suggested using Beer's Viable Systems Model within a Soft Systems framework involving the main stakeholders in Gippsland. We now turn to an explanation of VSM and how it might be utilized to involve the stakeholders. 


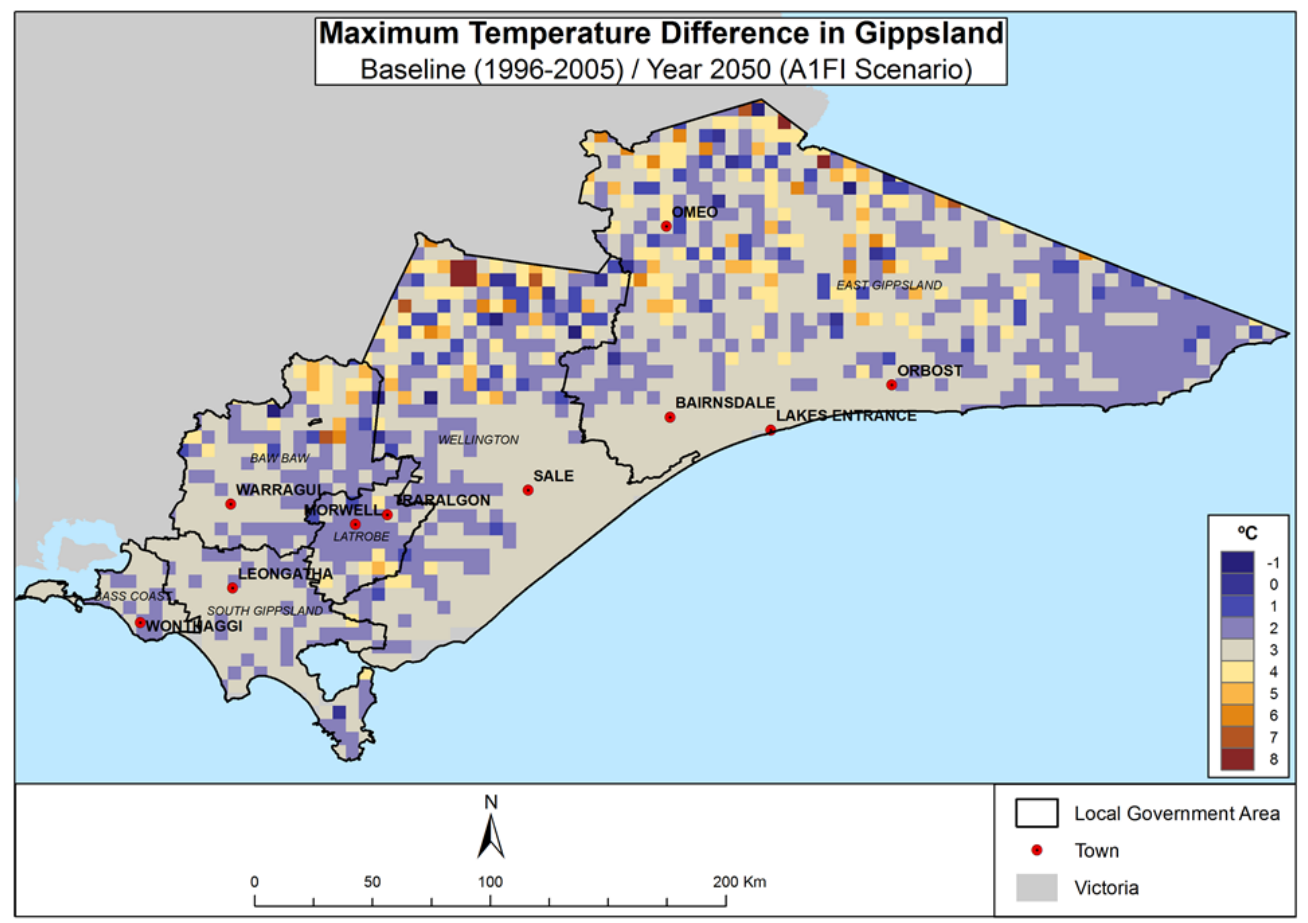

Figure 2. Predicted maximum temperature change for Gippsland in 2050, showing most areas having a 2 to 3 degree temperature rise.

\section{VIABLE SYSTEMS MODEL}

Beer's VSM is based on how the human body and its nervous system functions. In "The Brain of the Firm", Beer explains in some detail how the human body and its nervous system can be used as a model for the effective functioning of an organisation. The brain at the top of the diagram is connected to a central spinal column out of which are nervous system connections laterally to the limbs, heart, kidneys, skin, and other organs.

Beer deconstructs a viable organization into five subsystems, which correspond to different physiologic functions. System 1 represents an operating entity in a firm such as a production line or a purchasing department. Its equivalent human physiology is an organ such as the heart or a body part such as a hand or foot. System 1 does something and to function it must interact with the outside environment either receiving resources or providing products or information. Systems two to five represent the central nervous system or control function in an organization. System 2 monitors or supervises system 1 and acts as a communication channel to system 3. System 3 is concerned with resource allocation decisions to meet the overall organization objectives and the functioning of system 1 .

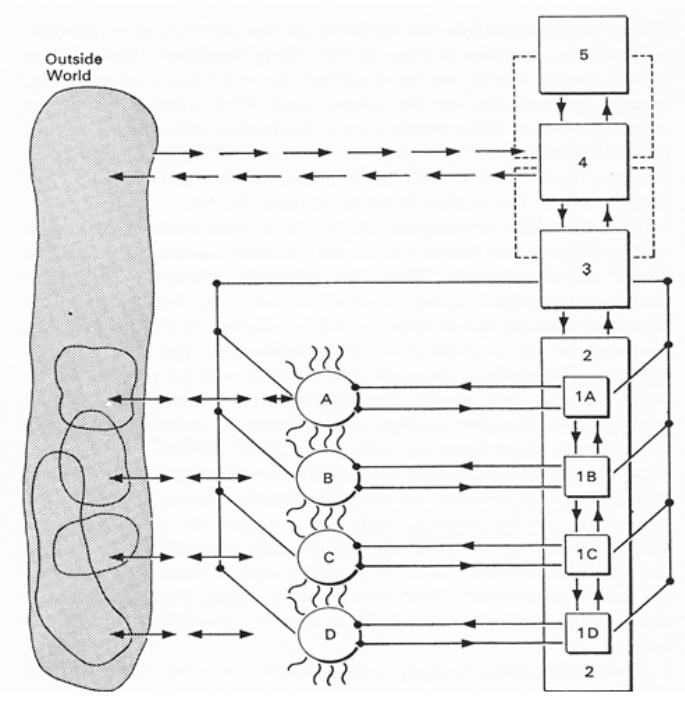

Figure 3 The autonomic system of a firm having subsidiaries $\mathrm{A}, \mathrm{B}, \mathrm{C}, \mathrm{D}$. (reproduced from (Beer 1981))
System 4 is concerned with monitoring the outside environment for changes that would threaten the viability of the organization. System 5 is "brain of the firm" represented by a board of management which sets the strategic objectives and governance of the organization. Figure 3 depicts a VSM showing the various subsystems and their interaction with the environment.

Beer also introduced the idea of recursion or systems within systems. This idea reflects the fact any organization can be deconstructed in smaller subsystems. These subsystems also need to be viable so that they must themselves contain the 5 sub systems. An example of this recursion, shown in Table 1 , is given for a farming system and the regional organization. 
Table 1. Typical examples of recursion for farming and government organizations.

\begin{tabular}{|l|l|l|}
\hline $\begin{array}{l}\text { Recursion } \\
\text { levels }\end{array}$ & Farming system & Regional organization \\
\hline 1 & Dairy Industry & Gippsland Region \\
\hline 2 & Dairy Marketing Association & Regional planners \\
\hline 3 & Dairy farming neighborhood & Local Government - e.g. Baw Baw Shire \\
\hline 4 & Individual farmer & Engineering Department \\
\hline 5 & A function - milking & Example: Road maintenance \\
\hline
\end{tabular}

\section{MOVES TOWARDS THE USE OF VIABLE SYSTEMS MODELS IN NATURAL RESORUCE MANAGEMENT.}

Figure 4 shows conceptually how two VSMs relate to the their joint environment. The operational tasks of the agricultural VSM by and large either draw resources from the environment or cause inadvertent impacts to the environment. One can compare this to the government services VSM where the interaction of the Systems Ones include deliberate actions to modify the environment to meet the perceived needs of the agricultural and indeed other systems of the society.

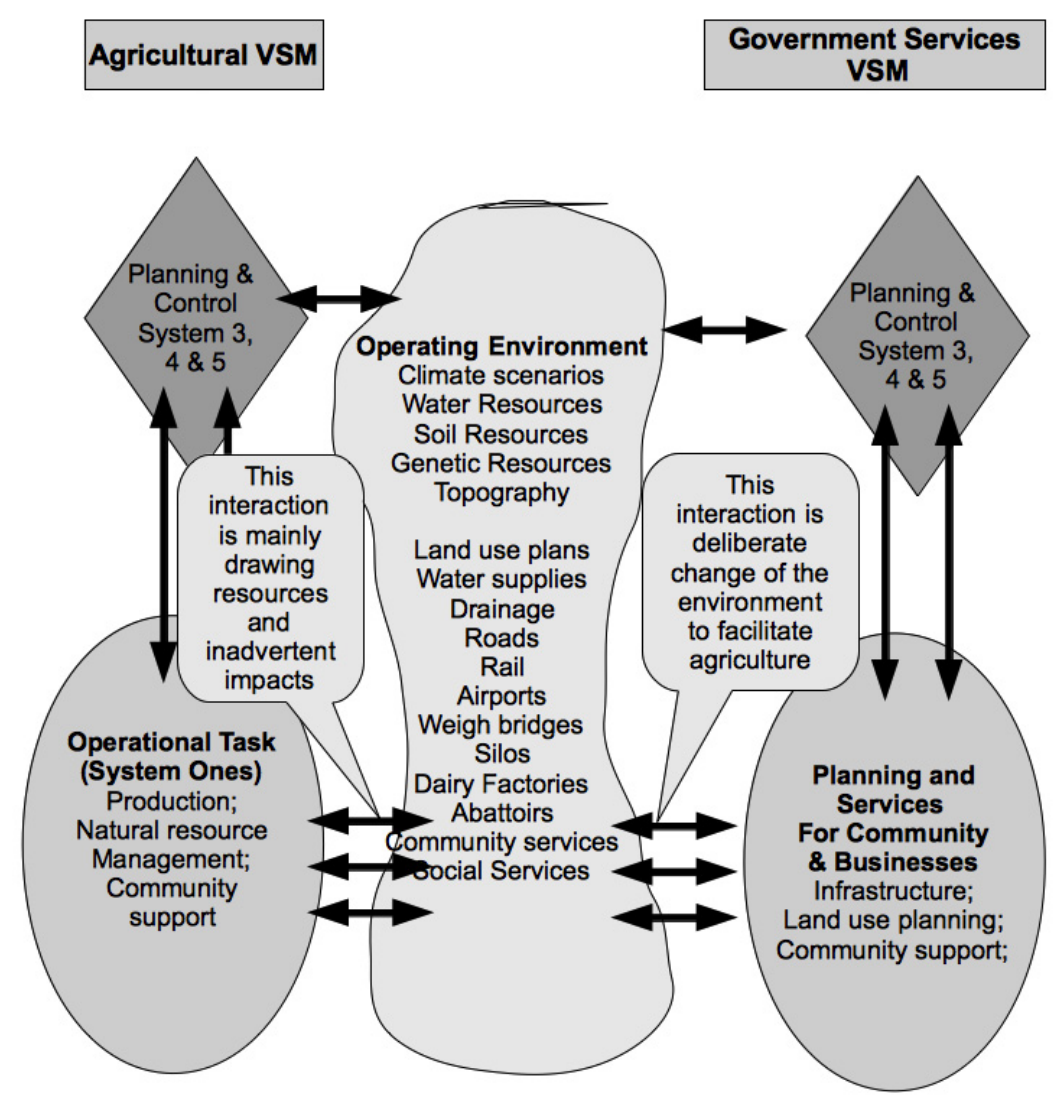

Figure 4. Relationship between the agricultural and government services VSM with their shared environment.

Apart from the physical impacts and use of resources, there is also a flow of information between the environment and the Systems 1 and 4 of the various VSMs. In order for the Government VSM to properly service the agricultural VSM an orderly repository of information would assist in their planning function. 
Similarly the agricultural VSM needs to be well informed about the state and trajectory of the environment in order to make good decisions.

Also related to the use of information, there is a need to judge whether a particular system is in fact viable. Bossel (2001) developed a comprehensive set of performance indicators that identified the essential components of a viable bio-ecological system. He further suggested that for a system to be viable it must devote an essential minimum amount of attention to satisfying the "basic orientors" that respond to the properties of its environment. In figure 4, the orientations of a system that must be satisfied

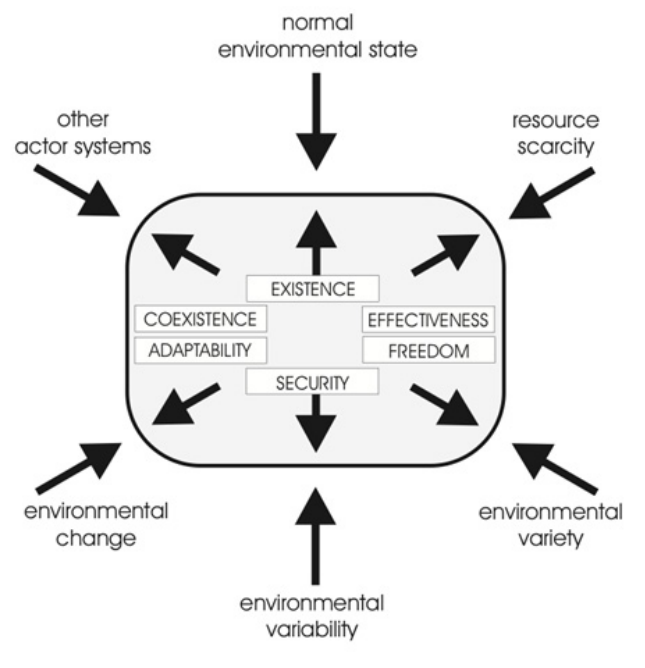

Figure 4. An illustration of the orientors of a system and the way they interact and responds to the environment for a system to be viable are illustrated. Each of these orientations are responding to aspects of the environment in which the system operates.

Bossel argues that if each of the orientations are not satisfied then eventually the system will prove to be non-viable. From a climate change adaptation perspective, in times of rapid change both the owners of the system and the government services providers need to have early warning of threats to viability. This is to allow effective decisions to be made on the part of the owner about either transforming or adapting a system before it ceases to be non-viable. Similarly, the suppliers of government services need early warning of non-viability so that they can either provide the services to ensure viability or assist an orderly transition to alternative enterprises.

In order to assess the various indicators a regional information system is proposed to gather and warehouse all of the relevant data to allow the VSMs to operate effectively and to provide the information for assessment of the viability of the systems.

Past research on devising indicators for sustainability and viable systems has shown that there is rarely immediate agreement on appropriate indicators. Reflecting on Figure 1 it can therefore be concluded that there is a plurality of objectives and that using systems thinking that assumes unitary objectives are less likely to be successful. In situations such as this Soft Systems Methodology has been used to find common ground among the stakeholders to allow progress on dealing with the issues at hand.

\section{DISCUSSION}

Gippsland, like other regions around the world, is likely to see unprecedented rates of change as a consequence of changing climate and structural adjustment by governments and business. The communities of the region as a consequence are facing a so-called 'wicked problem' in the sense that there is diversity of opinion as to what the problem is and what measures are likely to be useful in shifting the underlying issue to a preferable state. While some aspects of the issue are well understood and amendable to hard systems approaches, other aspects are exceedingly complex or are subject to a plurality of objectives of the various participants. In these situations, attempts to structure and model the situation using hard systems approaches are less likely to be successful.

Following the thinking of Jackson (2003) a methodology called Critical Systems Practice is being employed to investigate the issue. Where appropriate hard systems approaches are being used to generate base data to provide scenarios upon which other methods of investigation are founded. The essential element for continued prosperity of the region is adaptation of systems of economic and service activity. Viable Systems Modelling is being used to describe the agricultural and local government systems to facilitate and Soft Systems Methodology investigation of the systems. A key aspect of the investigation is to come to agreement on the indicators of viability for the systems that will in turn provide guidance on suitable information to be gathered, stored, and analysed in a regional information system. The indicators will in turn give guidance to planning and control functions of local government and agricultural enterprises on measures required for adaptation to ensure continued viability or, where necessary, transformation to new viable activities. 
Progress on research to date includes development of this framework and downscaling of climate change predictions to a grid resolution that can provide tangible scenarios for workshop participants in the grapple with.

\section{REFERENCES}

APSC, A. P. S. C.-. (2007). Tackling Wicked Problems: A Public Policy Perspective. Canberra, Australian Government: 38 .

Bawden, R., R. Ison and R. Packham (2010). Developing Systemic Competencies Course Manual. A short course. Sydney, Systems Development Institute Pty. Ltd.

Beer, S. (1966). Decision and control: The meaning of operational research and management cybernetics. London, Wiley.

Beer, S. (1981). Brain of the firm: The managerial cybernetics of organization. Chichester, J. Wiley

Bossel, H. (2001). " 2001. Assessing viability and sustainability: a systems-based approach for deriving comprehensive indicator sets. 5(2): 12." Conservation Ecology 5(2): 13.

Checkland, P. (2000). "Soft Systems Methodology: A Thirty Year Retrospective." Systems Research and Behavioural Science 17: S11 - S58.

Garnaut, R. (2011). Transforming the electricity sector. Canberra, Commonwealth of Australia.

Gordon, H., O'Farrell, S., Collier, M., Dix, M., Rotstayn, L., Kowalczyk, E., Hirst, T. and Watterson, I (2010). The CSIRO Mk3.5 Climate Model. CAWCR Technical Report No. 021

Jackson, M. (2003). Systems Thinking: Creative Holism for Managers. Chichester, John Wiley \& Sons.

Rittel, H. W. J. and M. M. Webber (1973). "Dilemmas in a general theory of planning." Policy Sciences 4(2): 155-169.

Sposito,V.A. and Faggian, R. (2011) "Multifunctional Agricultural and Rural Development;A Novel Approach to Confront Climate Change in Rural Regions", Discussion Paper, Future Farming Systems, Department of Primary Industry, Parkville, Victoria.

Wilson, G. A. (2007) Multifunctional Agriculture; A transition theory perspective, CABI, Oxfordshire, UK. 